\title{
A gift and calling
}

Healers: Extraordinary Clinicians at Work

David Schenck and Larry Churchill

Oxford University Press; 2011.

A s I begin my career, I will not be content to be only a diagnoser of diseases, a writer of prescriptions, an avoider of lawsuits. Although that is perhaps all my education has taught me.

So it was with interest that I began Healers, by Vanderbilt University ethicists David Schenck and Larry Churchill. With the subtitle Extraordinary Clinicians at Work, this book promised some insight into how to be something more than just a doctor.

Schenck and Churchill's work is centred on a qualitative study of interviews with 50 practitioners from the southeastern United States - mostly medical doctors, but also some practitioners from other disciplines such as chiropractic and traditional Chinese medicine, who had been identified by their peers as possessing "great skills in relating to their patients." With this approach, the authors implicitly subscribe to the notion that it is the relationship that heals. The subject of discussion, then, is a "healing" that can occur quite in the absence of any "curing."

With that fuzzy - by which I mean, without pejoration, both "imprecise" and "warm" - notion as a jumping off point,

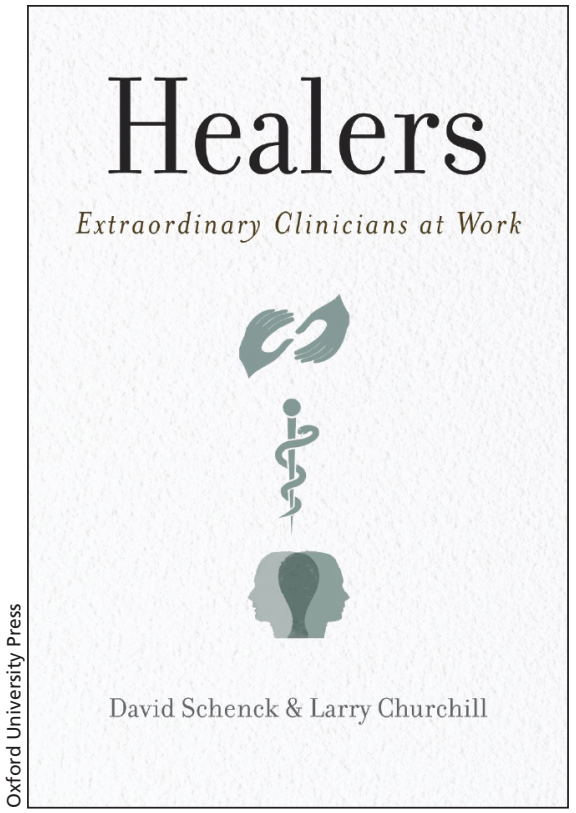

tion and hand-shaking variety), but focus instead on how the practitioner can create a healing space for the patient through openness, humility and authority.

And while relating physicianpatient contact to a ritual might at first seem to be an analogy, Schenck and Churchill soon make it clear that they take the role of spirituality to be crucial (no pun intended). Their healing ritual, whether it takes place in a sweat lodge or a downtown clinic, is just that. And the practitioner's most important task in this ritual is " ... complete surrender ... of all blockages and protection, of all

\section{A "healing" that can occur quite in the absence of any "curing."}

Healers begins by being surprisingly concrete and prescriptive: the reader is presented with a collection of behaviours that the clinician might use to turn a visit with a patient into what an anthropologist might call a healing ritual. They do not suggest superstition and recommend only a little ceremony (of the formal introduc- ego-orientation and armor, of all need for control and understanding." This is, of course, an approach quite different to the catechism of the orthodox medical curriculum.

The study's informants, at least those from whom we hear, consider themselves spiritual, as people and as practi- tioners (indeed, none of them is identified as aspiritual, never mind atheist; there will be no "healing" for acolytes of Dawkins and Hitchens, at least not in the Schenck-Churchill sense). Thus motivated, and armed with remarkable capacities to connect with patients, their experience and perspective are compelling. Perhaps ritualization of the spiritual connection between patient and doctor can result in healing, if not miracles.

Healers is at its weakest when it strays from practitioners' discussions of this central thesis. "Patient perspectives" are provided by excerpts from published authors, frequently marred by the effete attachment of considerable significance to trivial details: one writer feels "understood" because a doctor "squeezed ... my toe." A discussion of biomedical science, focused on the perception of pain, seems of limited relevance to the broader concept of healing that is in use. Perhaps most important, the skeptical reader will be unswayed by the thin scaffold of scientific evidence presented, and the believer will have no need of it.

These distractions aside, Healers makes you think. And Schenck and Churchill would like you to think that their approach to healing should be part of medical education, as an antidote to "a regimen of biomedical training all too often focused on ... a diseased body somehow separable from lives and worlds of the physician and patient." But is there a flaw of logic at the heart of Healers? If healing is "a matter of gift and calling," as the authors suggest, can that be taught? And even if it can, what am I to do, when my formal training is behind me?

Paul Moorehead MD

Pediatric hematologist/oncologist

Janeway Child Health and Rehabilitation

Centre

St. John's, NL

CMAJ 2013. DOI:10.1503/cmaj.121106 